\title{
Considerações sobre geografia e futebol: produção do espaço urbano e apropriação do território
}

\author{
Consideraciones sobre la geografia y el fútbol: producción del \\ espacio urbano y apropiación del territorio
}

Considerations about geography and football: The production
of urban space and ownership of the territory

\author{
Pedro Höfig \\ herr.hoefig@gmail.com \\ Universidade Estadual de Londrina
}

Claudio Roberto Bragueto

bragueto@uel.br

Universidade Estadual de Londrina

Resumo: Com base em levantamento bibliográfico, uma série de argumentos são apresentados fundamentando os vínculos profundos entre a ciência geográfica e o futebol. Buscou-se apontar a conexão entre território e futebol, procurando verificar como tal esporte apresenta-se como metáfora entre disputas territoriais. É por intermédio do futebol que as pessoas buscam territorialidade e o direito à cidade, refletindo as constantes lutas sociais e a realidade da população. A partir do estudo, observou-se que a geografia e o esporte estão intimamente ligados, tendo em vista as transformações importantes nos espaços urbanos apropriados para a prática desportiva.

Palavras-chave: Geografia. Futebol. Territorialidade.

Resumen: A través de un levantamento bibliográfico, una serie de argumentos son presentados fudamentando los vínculos profundos entre la ciencia geografica y el fútbol, buscando verificar como el fútbol interfiere en la concepción del territorio y además como deporte se presenta como una metáfora entre disputas territoriales. Es através del fútbol que el pueblo busca territorialidad y el derecho a la ciudad, reflejando las constantes luchas sociales y la realidad de la populación. A partir de este estudio se observó que la geografia y el deporte están intimamente unidos en lo que se refiere al territorio y al espacio, teniendo en cuenta las transformaciones importantes en los espacios urbanos apropiados para la práctica deportiva.

Palabras claves: Geografia. Fútbol. Territorialidad.

Abstract: Through a literature survey, many are here presented to express the link between the geographical science and football. More specifically, what this work 
intends is to show the connection between territory and football, trying to verify how one interferes on the other and, even further, how this sport can represent a metaphor of territorial disputes. It is through football that citizens can manifest their strive to territorialities and their rights to the city space, which is reflected in many struggles and in the social reality of the population. This study allows us to observe that Geography and Sport are tightly linked in what concerns territory and space, having in mind that transformations and urbanization of the area suitable for sports practice can also be noted.

Keywords: Geography. Football. Territorialities.

\section{INTRODUÇÃO}

O presente trabalho visa desenvolver algumas considerações sobre a relação existente entre geografia e esporte, porém, mais verticalmente, trabalha-se com o nexo entre a geografia e o futebol.

Com base em um levantamento bibliográfico, uma série de argumentos são apresentados fundamentando os vínculos profundos entre a ciência geográfica e este esporte. Mais especificamente, trata-se da conexão entre território e futebol, procurando verificar como este interfere na concepção daquele e, mais, como tal esporte apresenta-se como uma metáfora para disputas territoriais.

Outro aspecto abordado refere-se à crescente elitização do esporte mais consumido no Brasil, expondo o encarecimento dos ingressos e o crescente controle por medidas de segurança e conforto que existe dentro dos estádios como, por exemplo, a proibição de assistir aos jogos em pé.

Certamente, no contexto em que se encontra hoje, em que este esporte movimenta gradativamente mais dinheiro, o futebol se espacializa intensamente. A relação geografia/futebol expõe uma linha de raciocínio que faz com que entendamos com um pouco mais de lógica o espaço em que vivemos, uma vez que esta ciência contribui para uma melhor compreensão do espaço.

\section{GEOGRAFIA DOS ESPORTES}

Ainda que relacionar geografia e esporte soe um tanto estranho para alguns, várias pesquisas têm sido desenvolvidas nesta temática. Um dos principais autores que tratam do tema resume as principais preocupações exploradas pela relação entre geografia e esportes:

a) atividades esportivas na superfície da Terra e como a distribuição espacial dos esportes mudou ao longo do tempo;

b) o caráter mutante do cenário esportivo, a simbiose entre o ambiente esportivo e aqueles que dele participam; e 
c) a realização de prescrições para a mudança espacial e ambiental no ambiente esportivo (BALE, 2003, p. 5).

Portanto, tal relação envolve a análise do espaço e do lugar (BALE, 1993) e deve-se compreender que é necessário considerar o espaço como condicionante para a ação humana, impondo "barreiras" ou oferecendo "atrativos", e não como mero palco passivo do acontecer social (JESUS, 1999).

Não é por acaso que um esporte chega a determinado local: naturalmente, o fator histórico tem enorme importância, no entanto, a geografia do espaço é determinante. Em um país montanhoso se pratica mais alpinismo que em outro com topografia mais plana, onde se pratica mais o futebol. As diferentes relações que o homem estabelece com o meio em determinada região e as diferentes paisagens naturais forneceram bases para diversas modalidades esportivas do mundo atual. Assim como cita Huizinga (1996 apud GIULIANOTTI, 2002), a Inglaterra se tornou palco para a vida esportiva devido a sua topografia eminentemente plana.

Já no que se refere à valorização do espaço, podemos dizer que, muitas vezes, o esporte o valoriza, já que para sua prática, se constrói algo que incorpora trabalho. Tempo e qualidade de trabalho geram valor, que, no mercado, se traduz em preço. Até mesmo os parques públicos de lazer geram aumentos nos impostos. Assim, valoriza-se a área e fica inviável aos menos favorecidos financeiramente de permanecerem no local.

O estádio Engenhão, construído na Zona Sul do Rio de Janeiro, onde se localizava um campo de futebol amador, "expulsou" a população local, visto que, de repente, tornou-se caro viver por lá. Tal construção, oriunda dos jogos Pan-americanos de 2007, é considerada um "elefante branco", já que suas vias de acesso são precárias e inadequadas. O estádio, afastado, não possui utilidade frequente (no momento, está alugado pelo Clube de Futebol e Regatas Botafogo, mas toda a parte direcionada ao atletismo está praticamente abandonada), causando enorme prejuízo. Ainda sobre valorização do espaço, segundo Jesus (1999) os esportes da elite como, por exemplo, o golf, acabam por valorizar os terrenos localizados próximos ao campo. Chegando até a 80 mil hectares no Reino Unido, estes campos podem valorizar até 10\% estes terrenos vizinhos (BALE, 1989 apud JESUS, 1999). Segundo Bob Adams (apud JESUS, 1999), a maioria desses campos são construídos muito mais com o propósito de valorizar a área do que pela prática do esporte em si.

Ainda conforme as ideias de Jesus (1999), os hipódromos também são vistos positivamente para o mercado imobiliário. Com o crescimento das cidades e a expansão da indústria do espetáculo esportivo, vieram as melhorias, como a construção de arquibancadas e pavilhões sociais, visto que, anteriormente, as corridas de cavalo na Europa encontravam-se afastadas das cidades e sem nenhum tipo de valorização e estrutura. Isso começou com a reforma do Barão de Hausmann em Paris, quando foi construído o hipódromo do Antenil. Influenciadas pelo espírito da belle époque, a maioria das outras grandes cidades quiseram imitar a potência da época e acabaram por também construir hipódromos nos bairros elitizados. 
A especulação imobiliária também teve ligação com o futebol. Donos de loteamentos cediam áreas para que se criassem campos de futebol, valorizando, com isso, os terrenos em processo de ocupação. O local isolado, com o campo, atraía novos moradores e acelerava as vendas. Desta forma, com a zona densamente ocupada e com abundante oferta local de mão de obra barata, o campo era substituído por uma indústria.

Referindo-se aos megaeventos esportivos, como Jogos Olímpicos e Copas do Mundo, lidamos com a geopolítica, principalmente tratando-se do primeiro, que é utilizado como uma espécie de propaganda das potências econômicas. Devem ser considerados, ainda, os poderosos investimentos nas cidades que os sediam, podendo alterar toda a infraestrutura do local, essencialmente a rede de transporte. Barcelona, após as Olimpíadas de 1992, se transformou, sendo considerada hoje uma das mais belas cidades do mundo. Já no Rio de Janeiro, pós Pan-Americano de 2007, o que se verificou foram as privatizações de áreas de lazer, criações de obras com discutíveis utilidades e o emprego de verba pública onde deveria ser utilizado dinheiro privado. Tal fato causou dificuldade no orçamento básico da prefeitura nos meses e anos seguintes. No geral, a população não percebe todo o dinheiro público investido em algo que não terá retorno à população, já que

A cidade e a nação, embora não sejam conhecidos integralmente por cada uma das pessoas, são símbolos da fraternidade homem-lugar, os quais se constituem em um único ser. Os jogos esportivos são ocasiões em que este sentimento patriótico ou de bairrismo afloram, o que é uma relação simbiótica entre homem e meio ambiente (LEITE, 1998).

O que se percebeé a perda de capacidade de se sentir sujeito atuante. Muitas vezes, a utilização de dinheiro público é feita para dificultar o acesso da população à determinada área de lazer, elitizando o local ou até mesmo privatizando-o. No Rio pós-Pan, diversos locais onde a população adentrava livremente, hoje não são mais abertos ao público ou o preço é irreal para a grande maioria. Notoriamente, percebem-se novas políticas de acesso ao esporte (no caso tratado, futebol), tanto para a prática quanto para a mera apreciação. Os grupos sociais menos influentes perdem espaço no quesito político determinante ao acesso e controle das áreas onde se pratica o futebol. A especulação e valorização imobiliária reduzem o número de terrenos destinados à prática do esporte. Avisos como "proibido jogar bola", comuns na Europa, gradativamente tornam-se natural no Brasil e, com isso, a organização informal do futebol de rua perde força (GIULIANOTTI, 2002). Por outro lado, encontramos atualmente crescente número de centros de treinamento que, de outra forma, também produzem o espaço.

No que se refere ao acesso ao estádio, nota-se novamente uma exclusão: “os clubes passaram a considerar assentos como recursos escassos, aumentando o preço dos ingressos em temporadas e reduzindo a oportunidade de comprá-los na bilheteria" (GIULIANOTTI, 2002, p. 107). Isso nos diz que, após darem mais conforto aos espectadores, dificultaram o acesso. Desta forma, haverá uma diminuição da presença do público operário nos maiores estádio, população esta que sempre compareceu aos principais jogos desde a formação 
do futebol. (HORTON, 1997 apud GIULIANOTTI, 2002). As alterações estruturais nos estádios da Inglaterra são oriundas do Relatório Taylor, mas ignoram que tais reformas não deveriam excluir os torcedores de renda mais baixa (GIULIANOTTI, 2002).

No Brasil, a classe menos favorecida socialmente ainda tem seu espaço nos estádios e terrenos para prática do futebol. No entanto, embora aconteça com resistências, sabe-se que o clube (ou a cidade, na parte de lazer) que pretende prosperar tem de seguir a receita advinda da Europa. Gradativamente se reconhecem as alterações acontecendo, seja nas ruas, seja nos estádios. Com isso, o jogo se adéqua ao sistema e perde sua própria razão de existência.

Como se pode perceber, os equipamentos esportivos afetam diretamente a dinâmica urbana, cada um seguindo uma lógica locacional e uma forma espacial que deriva da própria modalidade esportiva que o criou (JESUS, 1999). Cabe ao geógrafo, portanto, enquanto agente de planejamento territorial, a partir de um diagnóstico socioambiental, ajudar a estabelecer as áreas mais a propriadas para a prática de cada esporte, minimizando, assim, impactos negativos sociais, culturais, econômicos e ambientais. Tratando-se de configuração territorial, os esportes merecem a observação dos geógrafos, uma vez que sua prática acarreta em transformações significativas na forma e na dinâmica do território.

\section{GEOGRAFIA DOS ESTÁDIOS}

Segundo o Instituto Cultural Itaú (1994, s/p.), “estádio, por definição, é o campo de jogos esportivos". Por ser obsessão popular, no Brasil, estádio é sinônimo de campo de futebol. Igualmente por este motivo, em nosso país, existe um grande número de estádios particulares, de posse dos clubes. No entanto, as famosas "peladas", nas quais os jogadores praticam o esporte nas ruas e parques, com diversas improvisações, desde a bola - que pode ser confeccionada com meias, por exemplo -, até os gols (chinelo, pedra, lata) e o espaço onde acontece o jogo, refletem a ideia de um futebol que já existia mesmo antes da regulamentação do mesmo.

Entretanto, desde o século XIX, a Grã-Bretanha já construía os estádios para os clubes, sendo estes localizados próximos a áreas de fácil acesso através de transporte público, especialmente ferroviários, viabilizando assim a presença de torcedores (INGLIS, 1987, apud GIULIANOTTI 2002). No que diz respeito à arquitetura, os projetos eram de caráter clássico no Reino Unido. Desenhados pelo arquiteto Archibald Leitch, possuíam forma elíptica, relembrando os anfiteatros romanos, e constavam de arquibancadas cobertas e abertas. Passado algum tempo, os campos passaram a ser construídos em forma retangular devido a limitações no orçamento e à disposição dos espaços nas cidades. Naturalmente, a classe alta se acomodava nos assentos onde a arquibancada fosse coberta. Em contrapartida, os operários ficavam em pé, sem cobertura e, na maioria dos casos, atrás do gol. Tal divisão resiste até hoje em determinados estádios (GIULIANOTTI, 2002). O antropólogo francês Christian Bormberger (apud GIULIANOTTI, 2002) acredita que as 
características da multidão são explicáveis de acordo com a parte favorita do campo para os torcedores.

Em Porto Alegre, nos dois maiores estádios (Olímpico e Gigante da Beira-rio), apesar da natural elitização, nota-se que torcedores ainda ficam em pé atrás do gol. Contudo, algumas inovações nessa mesma área do estádio aconteceram: no lugar do samba ritmado por instrumentos de carnaval, agora se ouve um som animado pelas batidas no bumbo, comum nas canchas de Argentina, Chile, Uruguai e outros países da América Latina. Ao invés das grandes bandeiras tremuladas por meio de varas de bambu, há predominância de pequenas bandeirolas e faixas esticadas na vertical.

A principal responsável por essa mudança, segundo Borges (2010), é a torcida Geral do Grêmio, que surgiu em 2001, quando torcedores da tradicional Torcida Jovem começaram a destoar dos demais componentes pela forma diferente de apoiar o time. As referências castelhanas, a avalanch $\mathrm{e}^{4}$ após os gols e o canto ininterrupto durante o jogo chamaram a atenção dos demais tricolores e o pequeno grupo transformou-se na principal força das arquibancadas. Alguns anos depois, veio a Guarda Popular do Internacional, que, apesar de negar a influência platina e deixar claro que é brasileira, assemelha-se ao grupo do arquirrival em sua forma de torcer. Assim como a Geral do Grêmio, a Guarda Popular aproveitou-se da acomodação das organizadas e, com suas músicas e letras diferenciadas, tornou-se importante.

Ainda segundo Borges (2010), a distinção diante das facções mais antigas e tradicionais ocorre por não serem torcidas organizadas: não possuem sede, carteirinhas e mensalidade. Outro fato interessante é o da grande maioria desses torcedores serem sócios-torcedores, ou seja, pagam mensalidade ao clube para obterem ingressos mais baratos que o comum (todavia, é muito mais caro do que era normal nessa área da arena: passou de $\mathrm{R} \$ 3,00$ para, nesse caso, $\mathrm{R} \$ 15,00)$. De fato, o público frequentador deste setor também se alterou.

Tratando-se de arquitetura e localização dos estádios, sabe-se que diversos fatores estruturais, sociais e geográficos influenciaram nas construções. Entretanto, tal descrição não é o intuito deste trabalho. Cabe a nós fazermos um breve histórico dos estádios em si.

Para familiarizarmo-nos com tal objeto, é de extrema importância conhecer uma parte de sua história. A origem do estádio remonta ao Império Romano, precisamente ao Coliseu. Este que em todo o tempo foi o modo encontrado pelos governantes para dar alegria e festas à população. Ademais, punições eram igualmente ali realizadas, revelando-nos um espaço de concentração, expressão e exercício do poder. Contudo, com a queda do Império, os estádios, como forma de evento social, desapareceram. Contudo, atividades lúdicas e eventualmente competitivas se realizam, como precursoras dos esportes modernos (GUTTMANN et al 1979 apud GAFFNEY; MASCARENHAS, 2004).

4 A cada gol, a torcida corre arquibancada abaixo. Essa ação encontra-se proibida na nova casa da torcida gremista, a Arena do Grêmio, inaugurada em dezembro de 2012. 
O que anteriormente figurava-se anormal passa a ser natural: a prática de jogos viris nos colégios ingleses. Com a dominação de grande parte do planeta conquistada pelos ingleses no século XIX, torna-se simples entender a prolixidade dos esportes em todo o mundo. Atentos à oportunidade de se lucrar, operadores privados profissionalizaram os esportes, visando grandes espetáculos. Como consequência, temos os grandes estádios da era moderna, que, diga-se de passagem, não são reservados apenas às elites, uma vez que tal objeto faz parte da estratégia dominante da reprodução social através do controle sobre o tempo livre do trabalhador (GAFFNEY \& MASCARENHAS, 2004).

Posteriormente, através dos governos nazifascistas, nos quais os esportes demonstram energia nacionalista e capacidade de realização de uma raça (GAFFNEY \& MASCARENHAS, 2004), os estádios propagam-se nas cidades. Já no Brasil, tal processo se inicia no período do Estado Novo (1937), tendo em vista que o futebol torna-se símbolo de patriotismo e da integração nacional, como foi o caso do Pacaembu (1940). Ademais, durante o período militar, enormes estádios são construídos em várias cidades, com ênfase nas capitais.

Atualmente, patrocinadores e receitas oriundas das transmissões dos jogos são as maiores fontes de renda dos clubes. Estádios lotados, portanto, passam a ser descartáveis. “Todos os lugares devem possuir cadeiras, impondo aos espectadores uma atitude inteiramente diferente, condicionada, vigiada, cerceando seus movimentos individuais e coletivos" (GAFFNEY; MASCARENHAS, 2004). Os clubes preferem, agora, clientes a torcedores. As famílias de classe média vão ao estádio pagar e consumir mais. Certamente, clientes se comportam melhor que torcedores.

Em nosso país, aos poucos, o estádio se liberta deste papel na reprodução social para ingressar na esfera do consumo elitizado de um espetáculo, através do Estatuto do Torcedor (2003). Desta forma, naturalmente reportamo-nos ao Maracanã, que teve sua chamada "geral" extinta. Lembramo-nos ainda do fim da "coreia" (a "geral" do BeiraRio). Tal fato foi noticiado pela imprensa local como "fim do romantismo do futebol gaúcho". Já em Curitiba, recordamo-nos do demolido estádio Joaquim Américo (1924), substituído pela Arena da Baixada, um dos símbolos da cidade "progressista e ordeira" (GAFFNEY; MASCARENHAS, 2004).

Desta forma, nota-se que os estádios sempre foram “[...] espaços de expressão do poder, concentração do poder e de uma dada forma de realização do poder" (GAFFNEY; MASCARENHAS, 2004, s/p.). São capazes de mobilizar uma nação inteira e cada indivíduo a seu modo, cumprindo a atribuição de local efêmero de uniformidade da coletividade, de modo que pode ser comparado a uma escola, por exemplo (COSTA 1987 apud GAFFNEY; MASCARENHAS, 2004).

Atualmente, as festas lúdicas e a expressão popular estão, gradativamente, perdendo espaço. Os clientes estão dominando os estádios e estes são facilmente controlados: se comportam como se estivessem em frente à televisão assistindo ao jogo. Em suma, o circo ao povo está sendo substituído pelo consumo: é o futebol moderno. É comum na Inglaterra ouvir declarações de jogadores, após a partida, dizendo que o estádio mais parecia um teatro. São mudanças estruturais importantes para humanizar o habitat hostil 
do futebol. Curiosamente, no mesmo país se encontram os hoolligans. Estes estão sendo excluídos dos estádios, o que, como tem sido visto, não elimina o problema da violência. Como já afirmado, as brigas são muito mais que atos de vandalismo: são um problema social.

A gradativa elitização mostra que o futebol faz parte dos interesses do capital. Expressa a imposição da lei da oferta e da procura em um comércio cultural e esportivo como qualquer outro. Isto é: não se trata de uma organização dentro do futebol que esteja contra os interesses do torcedor tradicional, mas, sim, da exclusão das pessoas que não têm poder de compra.

Até mesmo os jogadores passaram a ser mais controlados. Não se pode tirar a camiseta ao comemorar, momento extremamente emocional: o patrocínio não deve ser escondido no momento de maior destaque. Declarações polêmicas (leia-se, dizer a verdade) frequentemente são motivos de severas punições. A agressão e o desentendimento não vistos pelo árbitro, a famosa malandragem, acarretam em extensas suspensões após o monitoramento da televisão. E os jogadores bad boys, por onde andam? Não vem ao caso dizer se tudo isso é evolução ou regressão, todavia, o certo é que está mudando: o futebol, gradativamente, passa a ideia de algo politicamente correto, ainda que a verdade seja distinta.

Ainda que se altere o público dos estádios, de fato as pessoas ainda são apaixonadas pelo clube que vão prestigiar. "Os campos de futebol nem sempre são locais atrativos no sentido ornamental. Sua beleza é o tipo de ambiente especial, apreciado somente pelas pessoas que relacionam o cenário a seus vínculos emocionais" (HOPCRAFT, 1988 apud GIULIANOTTI, 2002). Um campo de futebol é visto como lindo apenas por quem ama o espetáculo ou o time ao qual foi assistir. Ver seu time, seu ídolo ou seu esporte traz sensações subjetivas. Dificilmente um torcedor se admira pela obra em si. Um apaixonado por futebol gosta de frequentar qualquer estádio por este remeter a emoções inigualáveis. Um torcedor se sente em casa no campo do seu clube, já que lá se sente representado. Portanto, "os campos de futebol possuem seu próprio caráter sociogeográfico, representativo da comunidade de torcedores" (GIULIANOTTI, 2002, p. 97).

Concordando com Bale (1993), o estádio é um gerador de sentimentos afetivos entre a pessoa e o lugar por movimentar uma porção do mercado voltada para o evento futebolístico (seja no âmbito local, seja em uma escala mais ampla) ou a partir do sentimento de lugar que por ele pode ser gerado quando o estádio é a casa de um time que representa uma comunidade ou uma cidade inteira.

A fisionomia dos estádios e seu objetivo se alteram. Entretanto, tratando-se de geografia urbana, os grandes estádios possuem um projeto arquitetônico que facilita a transição e fluxo dos espectadores em dias de grandes eventos. Assim sendo, estes estádios localizam-se, na maioria das vezes, em locais de maior movimentação de transportes públicos e maior concentração de vias de transporte. Ultimamente tem-se percebido uma tendência à construção de estádios em áreas menos urbanizadas, para que a necessidade viabilize investimentos na acessibilidade, conforme a demanda. Assim sendo, o estádio pode ser considerado um "objeto geográfico" capaz de modificar e 
reorganizar a área territorial a qual está situado, da mesma forma como os shoppings center o fazem. Entende-se, então, que os estádios estabelecem uma relação constante com a sociedade e a paisagem do território, modificando-os e sendo modificado por eles (JESUS, 1999).

\section{FUTEBOL E TERRITÓRIO}

Na contramão da grande maioria, que considera o futebol como uma arte por sua beleza estética e cultural, Gomes (2002) assim o reputa por sua capacidade de tornar estético algo banal nas lutas e relações sociais: a disputa territorial. De fato, o futebol metaforiza o choque de diferentes categorias existentes no dia-a-dia, seja numa guerra entre países, em assalto a uma mansão ou até mesmo em uma discussão sobre a posição do muro do vizinho.

Ainda conforme Gomes (2002), a bola de futebol é utilizada como um instrumento que demonstra posse e domínio de um grupo sobre o outro. É sua posição e deslocamento, durante o jogo, que explicita as forças e fraquezas das equipes. Com isso, domina-se o adversário. Entretanto, ao contrário dos combates territoriais que acontecem no mundo, o dominado pode, eventualmente, vencer. Ademais, neste esporte, há regras, igualdade de condições (em tese) e a violência é controlada. Assim, assistir a uma partida de futebol metaforiza uma disputa pelo espaço.

Portanto, é natural que tal esporte se difunda socialmente, haja vista que reproduz situações do cotidiano e representam setores, cidades, regiões, estados e nações que em nenhuma outra situação sentiram-se representadas. E é na arena onde tudo é posto em jogo: "o campo de futebol é um território, pois é a partir do seu controle e domínio que uma equipe impõe seu prestígio, superioridade e poder sobre a outra" (GOMES, 2002, p. 235).

Para Campos (2008) as identidades são criadas a partir do compartilhamento de representações sociais:

As identidades reagem à estrutura social, remodelando-a constantemente. É através da identidade futebolística que os torcedores se aglutinam social e espacialmente em torno de um clube. O compartilhamento de representações sociais gera um sentimento de pertença, formando-se, assim, as torcidas, que têm por característica a negação de outros clubes. Portanto, a identidade futebolística não se resume apenas a se identificar com um clube, mas também de negar os demais, principalmente os rivais (p. 257).

Em período de Copa do Mundo, todos se sentem representados e, naturalmente, torcem pela seleção do seu país se impor e mostrar ser melhor que as outras nações nesta diferente guerra mundial. Os jogos contra a Argentina têm suas peculiaridades: não importa o tipo de partida, devemos fazer-nos respeitados. Assim sendo, "a nação, essa imaginária comunidade de milhões, esse exercício de abstração difícil para as camadas populares, parece bem mais 'real' na forma de um time com onze pessoas e um nome" (HOBSBAWN, 1987, p. 171). 
No Brasil, o futebol é apontado como um importante elemento simbólico e fundamental fator de criação de uma estruturação identitária, sobretudo, em escala nacional, uma vez que foi capaz de reunir sob a mesma égide a elite e o povo, os símbolos nacionais e os valores populares. Entretanto, seria impossível considerar apenas a escala nacional em uma discussão acerca da prática social do futebol, que se dá no cotidiano. Os clubes e suas rivalidades reforçam o caráter local desta prática cotidiana, bem como produzem e fazem circular ricamente representações sociais (CAMPOS, 2008).

O Sport Club Corinthians Paulista, autodenominado o time do povo, possui torcedores espalhados por todo o país e, talvez por ser algo mais próximo e palpável que um país, é considerado ícone de pessoas que jamais sequer foram a São Paulo. No caso de Londrina, o Londrina Esporte Clube (LEC) representa toda a cidade e é raro encontrar um habitante que não sinta carinho pelo time. Raffestin (1993) acredita que o espaço construído pelos grupos sociais é o território. Sendo assim, mesmo que o norte do Paraná tenha, por diversas razões, uma relação muito próxima com São Paulo, o londrinense se sente identificado com o Tubarão ${ }^{5}$, já que este representa o lugar que ele ou seus antepassados ajudaram a construir. Sente-se a necessidade de valorizar o lugar e expor sua territorialidade.

O esporte e, particularmente, o futebol, é essencial na construção de identidade e referências territoriais. No entanto, para Gomes (2002), o que decreta e define uma torcida são elementos muito mais complexos do que apenas a proximidade de bairro. São estes outros fatores que influenciam na escolha de um clube ou em sua troca por outro de maior afinidade. Por exemplo, sabe-se que a mídia implicou diretamente no tamanho da torcida do Clube de Regatas Flamengo no nordeste do país, ao transmitir apenas jogos dos clubes do Rio de Janeiro. Soma-se a isso o fato de, nos anos de 1980, tal clube ter atravessado uma ótima fase. O gosto foi passando de pai para filho. Hoje, transmite-se também aos jogos dos times de São Paulo. Isso afeta diretamente a localização das torcidas. No Paraná, sabemos que o norte foi ocupado essencialmente por paulistas, ainda que um pequeno número de mineiros adentre a área no início de sua ocupação. No sudoeste, ocupado por gaúchos, nota-se a intensa presença de gremistas e colorados. Apenas no Paraná Tradicional é que se encontram os torcedores dos times de Curitiba. Portanto, a escolha do time está extremamente relacionada com as correntes migratórias e suas territorializações.

Em Londrina, percebemos que a maioria torcedora do Tubarão, frequentadora de estádio, possui mais de 40 anos. Atualmente, o clube ostenta um período de fracassos e a televisão não transmite os jogos. As maiorias dos habitantes torcem pelos clubes do estado de São Paulo; a TV não transmite nem os jogos dos considerados grandes clubes do estado do Paraná6. Mas, o que explica a paixão dos jovens da Torcida Organizada Falange Azul que jamais viu o time ganhar um título sequer? É a única forma de se sentirem

\footnotetext{
5 Apelido criado em 1977, momento em que o clube atravessava ótima fase e o filme Tubarão, de Steven Spielberg, fazia muito sucesso.

6 Ressalta-se, todavia, que o campeonato paranaense passou a ser transmitido pela RPC TV (afiliada da Rede Globo no Paraná) desde 2008.
} 
representados, pois existe dentro deste esporte a capacidade de representar e metaforizar todos os tipos de batalhas e lutas do cotidiano na cidade: as lutas sociais (GOMES, 2002).

As próprias denominações do jogo metaforizam a guerra: o impedimento mostra que a posição avançada em relação ao adversário gera uma situação irregular (denominada "fora de jogo", por exemplo, em inglês, francês e alemão); os jogadores são denominados pelas posições que ocupam no campo e os adjetivos utilizados são matador, habilidoso, guerreiro etc.; a equipe é uma esquadra; a bola é um tiro, canhão, petardo e pode ser interceptada, lançada, dominada, tomada e dividida; o campo pode, ainda, estar atacado, invadido, dominado, sob pressão. Existem ainda as infiltrações, contra-ataques, barreiras, ataques pelos flancos, táticas (GOMES, 2002).

Todo esse espírito de luta, naturalmente, extrapola os perímetros do campo e contagia a cidade. No Brasil, com uma sociedade extremamente desigual e fraturada, é normal que se encontrem dois ou mais tradicionais clubes nas grandes cidades: a elite, $\mathrm{o}$ povo e/ou os descendentes de determinado país. Todavia, tal fato se restringe à origem, uma vez que, atualmente, várias classes sociais torcem pelo mesmo clube. Muitas vezes tais clubes dividem o mesmo estádio: no Mineirão, Cruzeiro Esporte Clube e Clube Atlético Mineiro; no Maracanã, Fluminense Football Club, Clube de Regatas Flamengo, Club de Regatas Vasco da Gama e Botafogo de Futebol e Regatas. Estas torcidas ocupam locais predeterminados no estádio: são organizadas e delimitam seus territórios. A extensão para a cidade ocorre quando a polícia define percursos para cada torcida, seja na entrada ou na saída. "[...] [Os torcedores] instalam-se sobre os bancos, gritam pelas janelas, colocam bandeiras dos clubes para fora; em certo sentido, desfilam seu domínio pela cidade" (GOMES, 2002, p. 245).

É comum ouvir dessas torcidas cantos como: "quem manda nessa cidade sou eu", e a violência é algo que nem precisa ser citado, ganhando autonomia em relação ao espetáculo. Frequentemente lemos e ouvimos comentaristas moralistas que criticam tais pessoas, citando-os como "falsos torcedores que nem sabem a escalação do time". Realmente deve ser difícil para uma pessoa de classe média-alta, sempre bem estruturada e sentada juntamente do ar condicionado, entender o porquê de indivíduos irem ao estádio (ou ainda mais comum fora dele) para brigar. Nossa intenção não é fazer apologia à violência, mas tais comentaristas, formadores de opinião, deveriam compreender que independentemente do resultado do jogo, a cidade representa o terreno de disputa no qual os torcedores buscam dominar e delimitar seu próprio espaço (GOMES, 2002).

Esses cidadãos não se sentem representados e "um comportamento social distintivo necessita, para existir, criar um espaço próprio de ação e visibilidade" (GOMES, 2002, p. 248). Portanto, trata-se de um movimento social urbano que busca território para existir, tentando expor de quem é o poder para as torcidas visitantes de outras cidades (com mais rivalidade ainda se for da mesma), estados ou países. Ou seja: não são apenas vândalos que gostam de brigar e bagunçar, mas, sim, algo muito mais complexo e consequente de um sistema injusto que afeta, até mesmo, os países considerados de primeiro mundo, já que nosso sistema socioeconômico gera desigualdades em todo o planeta. É a busca de unidade que só encontrada ali. E é sabido que o ser humano aumenta sua capacidade de 
fazer absurdos quando está em coletivo, no qual os elementos lutam pela mesma razão e qualquer ideia distinta é hostilizada, ignorada ou perseguida. É com a sua torcida que o cidadão se sente parte de algo, em uma cidade (estado ou país) em que ele não se sente representado.

Nas palavras de Gomes (2002, p. 246)

A cidade passa a pertencer ao universo simbólico do futebol e às suas representações; o espaço urbano torna-se um campo de futebol, e a dinâmica se opera como na imagem das equipes, só existindo os lugares referentes aos dois grupos, e um deles deve afirmar seu poder sobre o outro. Este poder se traduz em um domínio territorial, ou seja, a cidade deve ser conquistada.

Em Londrina, devido à existência de apenas um clube com torcida, tal imposição ocorre de forma diferente. Os torcedores locais se impõem sobre os dos grandes clubes de São Paulo e Rio de Janeiro, protestando durante as festas que os últimos fazem ao comemorar títulos na Avenida Higienópolis. Outro fato que ocorre é, quando esses torcedores (denominados "do eixão" pela torcida do Londrina) vão ao estádio assistir aos jogos do Tubarão com a camisa de clubes como São Paulo, Flamengo etc., são forçados a retirá-las. Os torcedores do LEC consideram vergonhoso o fato de paranaenses torcerem por clubes de fora do estado e ignorarem o time da cidade. Mais uma forma de ostentação ocorre quando uma equipe de fora, especialmente de Maringá-PR, joga em Londrina. De todas as formas, eles mostram quem realmente "manda na cidade". Já nos jogos fora de casa, a torcida também mostra sua voz, seja com gritos de guerra, arrastões, bombas etc.

Referendando Campos (2008), os clássicos são, para os torcedores, os jogos mais importantes do ano, já que são uma disputa pela supremacia ante ao adversário tradicional, ou seja, são formas de disputa territorial. Geralmente, as rivalidades se manifestam de maneira mais intensa em escala local, envolvendo clubes da mesma cidade (dérbis) ou estado. Sendo assim, a relação de rivalidade propicia a criação e circulação de representações sociais, já que faz parte da vida cotidiana das pessoas. No caso supracitado, envolve-se apenas a questão de supremacia territorial entre as cidades, tendo em vista que a cidade de Maringá não possui mais clubes tradicionais.

Ademais, o que todos repudiam e buscam inibir é um instinto humano: desde criança, o ser humano impõe fisicamente sua força, autoridade e poder. É comum e natural brigas nas escolas ou em qualquer lugar. Portanto, estamos lidando com algo muito complexo, que envolve instinto humano e problemas sociais: reduzir isso a "vândalos que não têm o que fazer" é algo muito simplista.

Essas torcidas, indiferente se em Londrina ou nas cidades grandes, possuem um grande conhecimento geográfico e cartográfico de seus territórios. Existem comandos em todos os setores das cidades, sendo todos eles mapeados e representados os domínios. Perpetua-se pela geração, assim, da ideia de limites e fronteiras. Desta forma, nota-se que o futebol afeta diretamente a geografia da cidade, expondo toda a realidade e injustiças, das quais se inicia a conquista de um território urbano. 


\section{CONSIDERAÇÕES FINAIS}

A partir do estudo, observou-se que a geografia e o esporte estão intimamente ligados no que se diz respeito ao território e espaço, tendo em vista que se notam transformações, desenvolvimentos (aqui relacionado à teoria conservadora) e urbanização do espaço apropriado para a prática desportiva. Esta depende da topografia e relevo local para que se possam definir as modalidades mais apropriadas e viáveis. Além disso, existem inúmeros exemplos ao longo da história da construção de áreas de lazer com o objetivo de valorização e elitização do local.

Por intermédio de levantamentos bibliográficos, alcançamos algumas considerações sobre geografia e futebol e, com isso, buscamos relacionar a importância deste esporte no espaço urbano. Tratando-se de configuração territorial, o esporte materializado em estádio tem presença ativa nos arranjos geográficos do espaço e merecem a observação dos geógrafos, uma vez que sua prática acarreta em transformações significativas na forma, na dinâmica do território e em sua valorização. Tal fato pode ser constatado em Copas do Mundo, quando ocorrem poderosos investimentos nas cidades-sede, podendo alterar toda a infraestrutura do local.

A origem dos estádios remonta ao Império Romano, mas em nosso país, aflorou no período do Estado Novo (1937). Notoriamente, hoje em dia, percebem-se novas políticas de acesso ao esporte, tanto para a prática quanto para a mera apreciação. No entanto, o futebol metaforiza o choque de diferentes categorias existentes no cotidiano e, por isso, é tão difundido socialmente, haja vista que representa setores, cidades, regiões, estados e nações que em nenhuma outra situação sentiram-se representadas. Sendo assim, o esporte e, particularmente o futebol, é essencial na construção de identidade e referências territoriais, além de afetar diretamente a geografia da cidade, expondo realidades e injustiças do território urbano. $\mathrm{O}$ futebol se refere a um aspecto marcante das culturas de países, estados e cidades, construindo paisagens, relações e símbolos.

As pessoas se divertem de forma lúdica no campo. É através do futebol que o povo busca territorialidade e o direito à cidade, refletindo as constantes lutas sociais e realidade da população. É através do futebol que grande parcela da população busca mostrar "quem manda nessa cidade". E é diante da relação geografia/futebol que podemos entender e planejar o espaço com mais racionalidade.

\section{REFERÊNCIAS}

BALE, J. Sports geography. 2 ed. London: Routledge, 2003.

Sport, space and the city. London: Routledge, 1993.

BORGES, R. - Torcidas Gaúchas, 2010 - Disponível em: <http://espnbrasil.terra.com.br/futebol/ noticia/66761_MAIS+CASTELHANAS+E+MENOS+POPULARES+BARRAS+GAUCHAS+MUDAM+A+ CARA+DA+GERAL>. Acesso em: 28 set. 2010.

CAMPOS, F. R. Geografia e Futebol? Espaço de representação do futebol e rede socioespacial do futebol. Terr@Plural, Ponta Grossa-PR, v. 2, n. 2, p. 249-265, jul./ dez. 2008. 
ESTATUTO DO TORCEDOR - Lei n. 10.671, de Maio de 2003. Dispõe sobre o Estatuto de Defesa do Torcedor e dá outras providências. Disponível em: <http://www.planalto.gov.br/ccivil_03/leis/2003/ L10.671.htm>. Acesso em: 15 mar. 2012.

GAFFNEY, C.; MASCARENHAS, G. O estádio de futebol como espaço disciplinador. SEMINÁRIO INTERNACIONAL MICHEL FOUCAULT - PERSPECTIVAS, n.1, 2004, Florianópolis-SC. Anais ... Florianópolis: UFSC, 2004, p. 2-16.

GIULIANOTTI, R. Sociologia do futebol: dimensões históricas e culturais do esporte das multidões. São Paulo: Nova Alexandria, 2002.

GOMES, P. C. da C. Condição Urbana. Rio de Janeiro: Bertrand, 2002.

HOBSBAWM, E. Mundos de trabalho: novos estudos sobre história operária. Rio de Janeiro: Paz e Terra, 1987.

INSTITUTO CULTURAL ITAÚ. Cadernos cidade de São Paulo: Estádios. São Paulo: ICI, 1994.

JESUS, G. M. A Geografia e os Esportes: uma pequena agenda e amplos horizontes. Conexões: Educação, Esporte e Lazer, Campinas-SP, v. 1, n. 2, p. 47-61, dez. 1999.

LEITE, A. F. O lugar: duas acepções geográficas. ANUÁRIO DO INSTITUTO DE GEOCIÊNCIAS, n. 21, 1998, Rio de Janeiro-RJ. Anais... Rio de Janeiro: UFRJ, 1998, p. 9-20.

RAFFESTIN, C. Por uma Geografia do poder. São Paulo: Ática, 1993.

Recebido em 05/04/2012

Aceito para publicação em 30/05/2012 